\title{
Fatal anthrax infection in a heroin user from southern Germany, June 2012
}

T Holzmann (thomas.holzmann@klinik.uni-regensburg.de) ${ }^{1}$, D Frangoulidis ${ }^{2}$, M Simon $^{1}$, P Noll ${ }^{3}$, S Schmoldt ${ }^{2}$, M Hanczaruk $^{2}$, G Grass ${ }^{2}$, M Pregler ${ }^{4}$, A Sing 5 , 5 Hörmansdorfer ${ }^{5}$, H Bernard ${ }^{6}$, R Grunow ${ }^{6}$, R Zimmermann ${ }^{6}$, W Schneider-Brachert ${ }^{1}$, A Gessner ${ }^{1}$, U Reischl' ${ }^{1}$

1. Institute of Medical Microbiology and Hygiene, University Hospital of Regensburg, Regensburg, Germany

2. Bundeswehr Institute of Microbiology, Munich, Germany

3. Krankenhaus der Barmherzigen Brüder, Regensburg, Germany

4. District Health Office, Regensburg, Germany

5. Bavarian Health and Food Safety Authority (LGL), Oberschleißheim, Germany

6. Robert-Koch Institute, Berlin, Germany

Holzmann T, Frangoulidis D, Simon M, Noll P, Schmoldt S, Hanczaruk M, Grass G, Pregler M, Sing A, Hörmansdorfer S, Bernard H, Grunow R, Zimmermann R,

Schneider-Brachert W, Gessner A, Reischl U. Fatal anthrax infection in a heroin user from southern Germany, June 2012. Euro Surveill. 2012;17(26):pii=20204.

Available online: http://www.eurosurveillance.org/ViewArticle.aspx?Articleld=20204

Article submitted on 22 June 2012 / published on 28 June 2012

Blood cultures from a heroin user who died in June 2012, a few hours after hospital admission, due to acute septic disease, revealed the presence of Bacillus anthracis. This report describes the extended diagnosis by MALDI-TOF and real-time PCR and rapid confirmation of the anthrax infection through reference laboratories. Physicians and diagnostic laboratories were informed and alerted efficiently through the reporting channels of German public health institutions, which is essential for the prevention of further cases.

In early June 2012, a case of anthrax infection was identified in an injecting drug user in Germany. Anthrax wasn't suspected initially and the patient died on the day of hospital admission. Two days later anthrax was confirmed and the relevant authorities were informed. This report underlines the importance of considering anthrax as a possible diagnosis in injecting heroin users presenting with fever or sepsis at emergency rooms and of the rapid management of such cases.

\section{Clinical case description}

In early June 2012 an injecting drug user in their 505 presented at the emergency department of a hospital in the south of Germany, with a two-day history of worsening swelling and reddening at an injection site, nausea and dyspnoea. The patient had been on oral substitution therapy for two years. Moreover, a history of chronic hepatitis $C$ infection with liver cirrhosis was reported. In the next hours after admission to hospital, the patient developed respiratory failure and was transferred to the intensive care unit (ICU) where they were ventilated mechanically. An elevated white blood cell count $(15.9$ cells $/ \mathrm{nL}$ ), anaemia (haemoglobin $10.4 \mathrm{~g} / \mathrm{dL}$ ), thrombocytopenia (38 cells $/ \mathrm{hL}$ ), elevated procalcitonin (1.05 $\mathrm{ng} / \mathrm{mL})$ and hypokalaemia $(2.5 \mathrm{mmol} / \mathrm{L})$ were observed. Elevated liver enzymes, lowered coagulation parameters and extremely high levels of D-dimers $(236,364 \mathrm{ng} / \mathrm{mL})$ were pointing to multi-organ failure. Blood and urine cultures were sent to the Institute of Medical Microbiology and Hygiene, University of Regensburg. The patient's condition worsened and they died on the day of admission due to a septic shock with multi-organ failure and massive disseminated bleeding. At the time, there was no clinical suspicion of anthrax.

\section{Laboratory analysis}

Blood cultures (Becton Dickinson, Heidelberg, Germany) turned positive after 53 minutes of incubation. Gram-stained microscopy showed non-branching Gram-positive bacilli growing in chains. Subcultures presented typical growth of aerobic spore-forming bacilli without haemolysis. Matrix-assisted laser desorption/ionisation time-of-flight mass spectrometry (MALDI-TOF MS) identification revealed Bacillus cereus (Bruker Daltonics, Bremen, Germany). The patient's history led to reanalysis with the Bruker 'SR Database' that contains so-called security-relevant organisms, which correctly identified $B$. anthracis.

An initial set of molecular diagnostic tests was performed for confirmation at the Institute of Medical Microbiology and Hygiene, University of Regensburg. Briefly, a loopful of cells was suspended in $500 \mu \mathrm{L}$ of detergent buffer. The buffer consisted of TE ( $\mathrm{pH} 7.5$ ) containing $0.5 \%$ Triton X-100 and $0.25 \%$ Tween 20 . The suspension was heated at $95^{\circ} \mathrm{C}$ for 30 minutes with occasional shaking, sonicated for 1 minute, and heated again at $95^{\circ} \mathrm{C}$ for 30 minutes. After $10 \mathrm{~min}$ utes centrifugation at $11,000 \times \mathrm{g}$, the supernatant was passed through a $0.2 \mu \mathrm{m}$ sterile filtration membrane. Extracting genomic DNA from a boiled bacterial culture proved to be reproducible, easy-to-perform and rapid before [1]. The DNA was directly used as template for a series of real-time PCR assays performed with the Light Cycler PCR system (Roche Diagnostics, Mannheim, 


\section{FIGURE}

Real-time PCR amplification plots (A) and melting curve analysis (B), anthrax infection, Germany, June 2012

A

\section{Amplification curves}

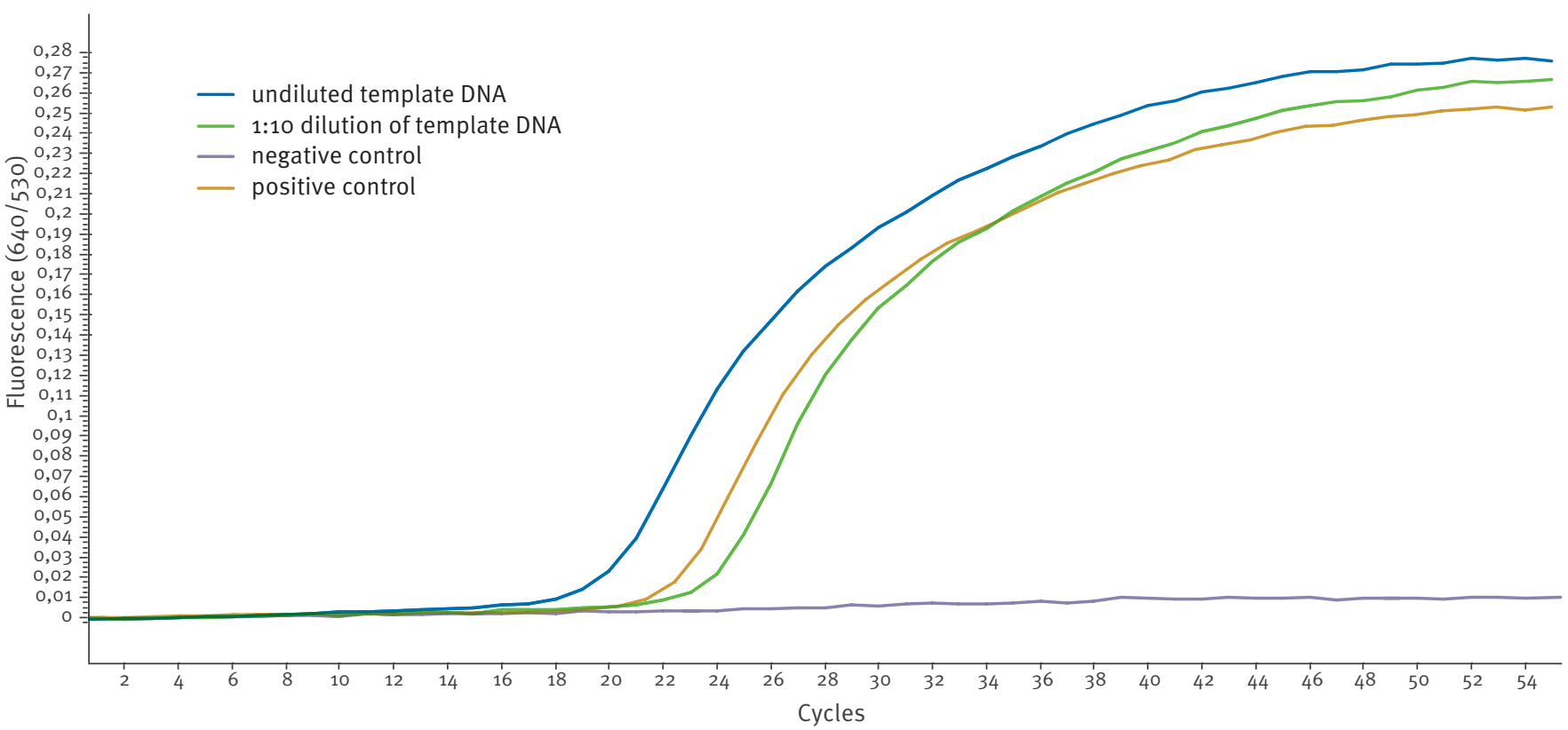

B

Melting peaks

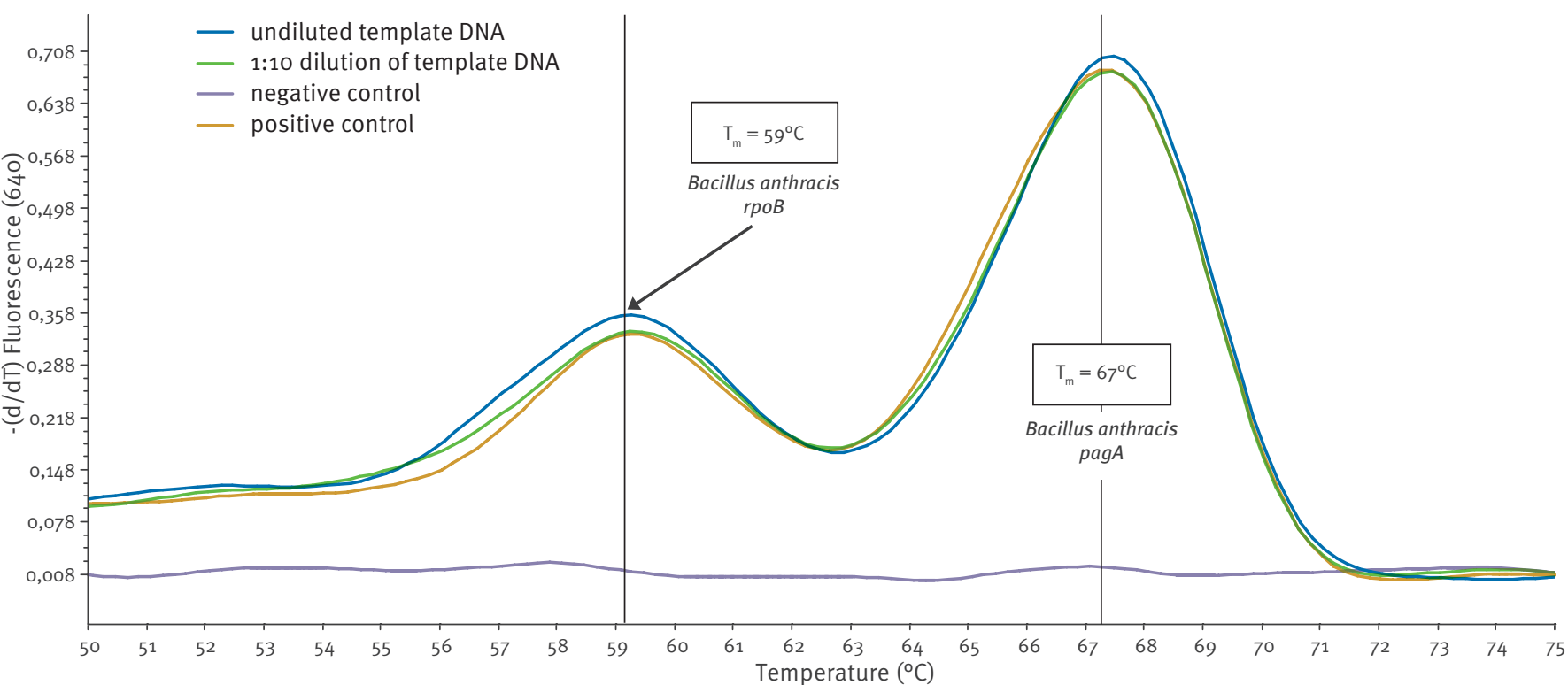

$\mathrm{T}_{\mathrm{m}}$ : melting temperature.

LightMix Bacillus anthracis PCR Kit (testing $5 \mu$ l aliquots of the original and 1:10 diluted template DNA preparations, respectively). 
Germany). The real-time assays included an in-house protocol for pan-bacterial 16S rDNA amplification and the LightMix kit $B$. anthracis (Cat. No: 40-0252-16, TIB Molbiol, Berlin, Germany). The kit is designed to detect the $\operatorname{pag} A$ gene as marker for the plasmid $\mathrm{pXO} 1$ and $a$. anthracis-specific segment of the bacterial rpoB gene for species identification, using hybridisation probes. Early crossing points (around cycle 18) and the specific melting points of the respective target genes pagA and $r р о B$ were observed in the melting curve analysis, indicating the presence of $B$. anthracis carrying at least the virulence plasmid $\mathrm{pXO}_{1}$ (Figure).

To substantiate the initial test results, an aliquot of the DNA preparation was sent to the Bundeswehr Institute of Microbiology in Munich. The initial PCR results were confirmed and extended using PCR assays for the capC gene (marker for the second virulence plasmid $\mathrm{pXO}_{2}$ ) and an additional chromosomal marker highly specific for $B$. anthracis (dhp61) [2]. First results of molecular genotyping of the strain showed close relationship to strains from a large anthrax outbreak among IDUs in Scotland [3].

\section{Control measures}

The District Health Office was informed about the suspected case of human $B$. anthracis infection immediately after obtaining the PCR results. Their experts got involved in the management of the case in close contact with the diagnostic institutions, the police authorities and the Task Force Infectiology of the Bavarian Health and Food Safety Authority (LGL).

\section{Box 1}

Timeline of events, fatal case of anthrax infection, Germany, June 2012

\begin{tabular}{|c|c|}
\hline \multirow[t]{4}{*}{ Day 1} & - Patient admitted to the hospital \\
\hline & - Blood cultures sent to the laboratory \\
\hline & - Patient dies due to septic shock \\
\hline & $\begin{array}{l}\text { - Blood cultures positive with Gram-positive bacilli } \\
\text { (late afternoon) }\end{array}$ \\
\hline \multirow[t]{4}{*}{ Day 2} & - Growth of Bacillus spp. on subcultures \\
\hline & - MALDI-TOF: Bacillus cereus \\
\hline & - Discussions on anthrax suspicion \\
\hline & $\begin{array}{l}\text { - Different PCRs and } 16 \mathrm{~S} \text { sequencing } \\
\text { over night }\end{array}$ \\
\hline \multirow[t]{4}{*}{ Day 3} & - B. anthracis confirmed by PCR \\
\hline & - Information of local health authorities \\
\hline & $\begin{array}{l}\text { - Involvement of regional and national health and } \\
\text { police authorities }\end{array}$ \\
\hline & - DNA sent to Bundeswehr Institute of Microbiology \\
\hline \multirow[t]{2}{*}{ Day 4} & $\begin{array}{l}\text { - B. anthracis confirmed using } \\
\text { further PCRs }\end{array}$ \\
\hline & $\begin{array}{l}\text { - Robert Koch Institute promotes further } \\
\text { information at national and international level }\end{array}$ \\
\hline
\end{tabular}

MALDI-TOF MS: matrix-assisted laser desorption/ionisation time-of-flight mass spectrometry.
Health officials considered contaminated heroin or cutting agents mixed with the heroin as possible source of the infection. Further investigations by the German police authorities were initiated immediately.

The competent public health authorities at national level were informed immediately about the confirmation of $B$. anthracis. The information on the occurrence of the case was distributed to the public health authorities in all 16 German federal states, at international level through the Early Warning and Response System (EWRS) of the European Commission and via ProMEDmail [4]and according to the International Health Regulations (IHR). In Bavaria, the medical associations were informed. Substance abuse counselling agencies were contacted nationally and at European level through the European Monitoring Centre for Drugs and Drug Addiction (EMCDDA) in order to spread the information among drug users. Additional information and materials were published by the public health institutes on their websites.

\section{Identification of the second case}

Two weeks after the first case was admitted to hospital, a second case of anthrax was identified in an IDU from the same region as the first case. The patient is stable under antibiotic therapy after surgical debridement [5]. The raised level of awareness created with the first case lead to a much faster workflow in the laboratory analysis in the second case. $B$. anthracis was confirmed three hours after blood cultures turned positive.

\section{Discussion}

Injectional anthrax has first been reported 1988 as fourth route of infection besides cutaneous, gastrointestinal and inhalational anthrax infections [6]. The first anthrax case related to injecting drug use was described 2000 from Norway [7]. There were no subsequent reports of injectional anthrax until 10 December 2009 when anthrax was identified in blood cultures from two injecting drug users from Glasgow, Scotland [8]. In the following months an increasing number of cases were identified [9]. By the end of the outbreak in December 2010, there were 47 confirmed cases of injectional anthrax (including 13 deaths), 35 probable cases (including one death) and 37 possible cases in Scotland and five cases including four deaths in England [3]. There were two confirmed cases in Germany related to this outbreak, including one fatal case [10]. The favoured outbreak hypothesis assumed that heroin had been in contact with goat skin contaminated with anthrax spores during transportation to Scotland [3]. Risk factors for infection were longer injection history, receiving opioid substitution therapy, and alcohol consumption [11]. All cases of injectional anthrax reported so far including the case presented here were not associated with the typical black escharseen in patients with cutaneous anthrax [12]. 
Because $B$. anthracis is seen very rarely in Germany and other developed countries, laboratory staff and clinicians should raise their attention when Grampositive bacilli growing in chains are detected in clinical specimens (Box 2).

$B$. anthracis cannot be reliably distinguished from $B$. cereus by growth characteristics, bacterial cell morphology or biochemical methods. The applicability of MALDI-TOF-MS for the identification of $B$. anthracis was demonstrated elsewhere [13]. Because of safety regulations, $B$. anthracis and other potential bioterroristic agents are not included in the manufacturer's (Bruker Daltonics) database. As in our case, the isolate is classified as $B$. cereus with the standard databases. Using a special database, containing the missing spectra, $B$. anthracis is identified correctly. The manufacturer discourages the standard use of the $B$. anthracis spectra due to misidentification of members of the $B$. cereus group. Consequently, the result ' $B$. cereus' in combination with a patient's history of injecting drug use should lead to further diagnostic steps. To differentiate between $B$. anthracis and non-anthracis Bacillus species harbouring anthrax-specific virulence plasmids, PCR targeting a chromosomal marker should be performed in addition to PCR assays covering the virulence plasmids $\mathrm{pXO}_{1}$ and $\mathrm{pXO}_{2}$. Non-pathogenic $B$. anthracis strains not containing plasmids can be identified using this combination as well $[2,14]$.

\section{Conclusions}

Health professionals and diagnostic laboratories should consider anthrax as a possible diagnosis in injecting heroin users presenting with fever or sepsis at the emergency room. The observed re-emergence of drug-related anthrax in Germany supports the hypothesis that heroin may provide a continuing entry route of $B$. anthracis into western Europe.

\section{Acknowledgements}

We would like to thank the clinical colleagues at the collaborating Hospital Barmherzige Brüder, Regensburg, for providing further details of the case, $\mathrm{H}$. Körber from the GA Regensburg for coordinating anamnestic investigations and reporting activities on district/local level, Silvia Förster, for her excellent technical assistance in performing the various PCR assays, as well as Jürgen Wenzel for his helpful comments on the manuscript. Moreover, we would like to thank Olfert Landt from TIB Molbiol, Berlin, for his continuous support and for providing specialized primer and hybridization probe oligonucleotides at very short notice for supplementary testing of the bacterial strain.

\section{Box 2}

Recommendations and lessons learnt from the fatal case of anthrax infection, Germany, June 2012

- When growth of Bacillus cereus sensu lato is identified by the MALDI species typing database, a sound anamnesis of the underlying clinical case should be performed.

- Suspicious cultures should be transferred to a biosafety level 3 environment and, whenever possible, a spectrum of validated molecular tests should be kept in stock for level 3 pathogens (especially anthrax).

- An agreed case definition and protocol for alerting the authorities should be available and known to all microbiologists and clinicians.

- Appropriate reporting channels should be maintained and exercised by the public health authorities to prevent that similar (or parallel) cases remain undetected.

- Confirmatory PCR testing in a specialised laboratory should be immediately requested. Diagnostic laboratories should know such specialised laboratories in their vicinity for support and check the logistics of sample transport in a situation of emergency (ideally before they encounter their first uncommon strain).

- Clinicians and microbiologists should be trained on a regular basis in the identification of anthrax and other rare infectious diseases that are highly pathogenic. 


\section{References}

1. Reischl U, Pulz M, Ehret W, Wolf H. PCR-based detection of mycobacteria in sputum samples using a simple and reliable DNA extraction protocol. Biotechniques. 1994;17(5):844-5.

2. Antwerpen MH, Zimmermann P, Bewley K, Frangoulidis D, Meyer H. Real-time PCR system targeting a chromosomal marker specific for Bacillus anthracis. Mol Cell Probes. 2008;22(5-6):313-5.

3. Health Protection Scotland. An outbreak of anthrax among drug users in Scotland, December 2009 to December 2010. Glasgow: Health Protection Scotland; December 2011.

Available from: http://www.documents.hps.scot.nhs.uk/giz/ anthrax-outbreak/anthrax-outbreak-report-2011-12.pdf

4. ProMED-mail. Anthrax - Germany: (Bavaria) fatal, heroin user. Archive Number 20120612.1165823. 12 Jun 2012. Available from: http://www.promedmail.org/direct. php?id=20120612.1165823

5. ProMED-mail. Anthrax - Germany (02): (Bavaria) Second heroin case, request for information. Archive Number 20120621.1175326. 21 June 2012. Available from: http://www. promedmail.org/direct.php?id=20120621.1175326

6. Lalitha MK, Anandi V, Walter N, Devadatta JO, Pulimood BM. Primary anthrax presenting as an injection "abscess". Indian J Pathol Microbiol. 1988;31(3):254-6.

7. Ringertz SH, Hoiby EA, Jensenius M, Maehlen J, Caugant DA, Myklebust A, et al. Injectional anthrax in a heroin skin-popper. Lancet. 2000;356(9241):1574-5.

8. Ramsay CN, Stirling A, Smith J, Hawkins G, Brooks T, Hood J, et al. An outbreak of infection with Bacillus anthracis in injecting drug users in Scotland. Euro Surveill. 2010;15(2): pii=19465. Available from: http://www.eurosurveillance.org/ViewArticle. aspx?Articleld $=19465$

9. Booth MG, Hood J, Brooks TJ, Hart A, Health Protection Scotland Anthrax Clinical Network. Anthrax infection in drug users. Lancet. 2010;375(9723):1345-6

10. Radun D, Bernard H, Altmann M, Schöneberg I, Bochat V, van Treeck U, et al. Preliminary case report of fatal anthrax in an injecting drug user in North-Rhine-Westphalia, Germany, December 2009. Euro Surveill. 2010;15(2): pii=19464. Available from: http://www.eurosurveillance.org/ViewArticle. aspx?Articleld $=19464$

11. Palmateer NE, Ramsay CN, Browning L, Goldberg DI, Hutchinson SJ. Anthrax Infection Among Heroin Users in Scotland During 2009-2010: A Case-Control Study by Linkage to a National Drug Treatment Database. Clin Infect Dis. 2012 Jun 18. [Epub ahead of print].

12. Hicks CW, Sweeney DA, Cui X, Li Y, Eichacker PQ. An overview of anthrax infection including the recently identified form of disease in injection drug users. Intensive Care Med. 2012;38(7):1092-104.

13. Lasch P, Beyer W, Nattermann H, Stammler M, Siegbrecht E, Grunow R, et al. Identification of Bacillus anthracis by using matrix-assisted laser desorption ionization-time of flight mass spectrometry and artificial neural networks. Appl Environ Microbiol. 2009;75(22):7229-42.

14. Ellerbrok H, Nattermann H, Ozel M, Beutin L, Appel B, Pauli $G$. Rapid and sensitive identification of pathogenic and apathogenic Bacillus anthracis by real-time PCR. FEMS Microbiol Lett. 2002;214(1):51-9. 